\title{
Electrical Heating Emissions on the Island of Ireland
}

\author{
William D. Kerr, David M. Laverty, and Robert J. Best
}

School of Electronics, Electrical Engineering and Computer Science, Energy, Power and Intelligent Control (EPIC), Queen's University Belfast, Belfast, Northern Ireland

\begin{abstract}
This paper shows the effect on household greenhouse gas emissions if standalone or supplementary electric heating was to replace conventional heating methods, based on the present day electrical grid. While having the capability to improve future grid effectiveness and dynamic stability through the potential incorporation of demand side management (DSM). The All-Ireland system has been used in this paper as an example of a network which has been experiencing a significant increase in renewable generation. To show the potential of the electric heating methods the characteristics of existing domestic heating systems will be discussed, in terms of their heat output against their exhaust emissions $(\mathrm{gCO} 2 \mathrm{e} / \mathrm{kWh})$. This will then be compared to that of the grid $\mathrm{CO} 2$ Intensity, showing the frequency and duration of the possible emission savings involved when using electricity as a main or supplementary heating source.
\end{abstract}

\section{Introduction}

As the EU has introduced strict emissions polices, and the Paris Agreement has been implemented, both the Republic of Ireland (ROI) and Northern Ireland (NI) have set targets of $40 \%$ RES-E (Renewable Energy Sources - Electricity) by 2020 [1], [2]. This is part of the strategy to obtain $16 \%$ of all energy consumed from renewable sources. To achieve this RES-E figure both Irish jurisdictions aim to provide $37 \%$ of their electric energy from wind generation [3].

Operating with such a high infeed of wind generation presents challenges with regards to system stability, due to low inertia. Presently, the system operator limits 'system non-synchronous penetration' (SNSP), of which wind is a leading contributor.

The SNSP problem is amplified on the island of Ireland as the island currently only has two low capacity DC interconnectors with Great Britain (GB). Meaning unlike countries such as Denmark which can achieve extremely high SNSP levels due to their heavily interconnected system [4] and ability to export large volumes of energy, while maintaining a high level of synchronous generation online [5]. The All-Ireland grid currently operates with an SNSP of up to $65 \%$, at this point the SNSP is curtailed due to stability concerns [5].

Plans are underway to increase the SNSP limit up to $75 \%$. A $5 \%$ increase is proposed to be trialled in the first quarter of each year [5] to identify the technical challenges that must be addressed. This transition of the system (generation and demand) is necessary, as without this the 2020 RES-E targets would be economically impossible to reach due to the amount of wind dispatchdown. This paper considers that the dynamic stability problem faced by the island, managed by the SNSP limit, is not that of oversupply of wind generation, but underutilisation of the potential RES-E resource.

The use of installed electric heating to provide support for the grid, in addition to its role in replacing conventional household heating methods, may help with this SNSP problem. With the use of a communication network in the future, electric heaters could be used for demand side management (DSM) and help push the island towards the $75 \%$ target.

Presently in Ireland, residential space and water heating accounts for approximately $19 \%$ of the total energy consumption of the country [6], [7]. Of this heating there is a modest amount of installed domestic electric heating on the island, with the latest census data showing the Rep. of Ireland having 13.5\% electric central heating and Northern Ireland having 5\% electric central heating [8], [9].

This paper looks at the effect of implementing electric heating on household emissions in the immediate term. A fuller picture of the $\mathrm{CO}_{2} \mathrm{e}$ intensity per $\mathrm{kWh}$ of the All-Ireland grid, in terms of the Well-to-Socket (WTS) emissions has been shown, covering all aspects associated with electrical generation, giving a more realistic emissions figure of the electricity used within the household. The emissions figures in this paper have also been broken down into the different tariff categories showing that contrary to some popular opinions, the offpeak emissions are actually higher than that of on-peak.

\section{Potential Emission Benefits of Electrification}


On the island of Ireland, the lack of mains gas infrastructure and a sparse and rural population density means a high percentage of households use oil heating. ROI has approximately $40 \%$ oil central heating households and NI has around $74 \%$ oil central heating households (this NI figure considers households with multiple heating source, one of which is oil) [8], [9]. Due to the high use of this carbon intense fuel, electric heating may provide a viable alternative to conventional central heating systems as a means to reduce emissions in the domestic energy market. To determine the benefits, the authors have performed a comprehensive study of fuel types, combustion appliances and electricity generation trends and time of use. For both electrical and combustion heating, the authors consider well-to-tank emissions as well as the emissions arising from the fuel itself.

The electricity grid data was provided by EirGrid, including data obtained via their 'Smart Grid Dashboard' [10]. The heating system efficiency data was taken from the latest 'Building Research Establishment Domestic Energy Model' (BREDEM) document [11]. The data for both grid and heating systems was used alongside DECC data for calculating an overall emissions picture [12].

\subsection{Point of use electricity breakdown}

Previous studies which have investigated the effect of household electrification on $\mathrm{CO}_{2}$ emission have made some crucial misjudgements [13], [14], [15]. In their comparisons they have only considered the emissions due to the burning of the actual fuel. This may be slightly misleading, as the process of electrical generation and distribution has much more energy loss than that of fuels burnt at the point of use, such as gas and oil. This study considers emissions of electrical energy produced on the island. If all aspects are considered from acquirement of fuel right to point of use, the losses in the electricity supply process increases the emissions by approximately $25 \%$ above that of the generation alone (based on data from 2014 and 2015, shown in Table 1). Whereas if all aspects are considered for fuels burnt at the point of use for conventional heating methods, gas emissions increase by only $13.4 \%$, with oil increasing by $20.7 \%$. This means that the emission saving shown in these studies, and many others, are not necessarily true in practice, as they have increased emissions in other economic categories and then not considered them in their specific area.

For actual comparison purposes, it is reasonable to use All-Ireland data due to the fact the island is considered to be one entity for SNSP level. From the data retrieved from EirGrid, it was found that the $\mathrm{CO}_{2}$ intensity did not include 'house load' (power to run generation plant). Due to this, the generation and emission data was used to calculate a more accurate figure. Emissions data was provided in the form of $\mathrm{tCO}_{2} / \mathrm{hr}$, mean only $\mathrm{CO}_{2}$ intensity could be found. DECC produces data in $\mathrm{CO}_{2} \mathrm{e}$, so considers nitrous oxide $\left(\mathrm{N}_{2} \mathrm{O}\right)$ and methane $\left(\mathrm{CH}_{4}\right)$ as the other contributors to the global warming effect of combustion emissions. To convert this to $\mathrm{CO}_{2} \mathrm{e}$ intensity, figures from DECC for the UK were used to scale the EirGrid data [12], this scaling method was used considering the similar climate and largely similar generation fuel mix of the UK.

The calculated figure for $\mathrm{CO}_{2} \mathrm{e}$ intensity $\left(\mathrm{gCO}_{2} \mathrm{e} / \mathrm{kWh}\right)$ was for the transmitted generation, meaning the power directly exported on to the network from generation plant. For comparison purposes, the emissions from the well to the point of use needed to be considered, as is the case for fossil fuel heating technologies (shown in Section 2.3). Again, using DECC figures the full breakdown of $\mathrm{CO}_{2} \mathrm{e}$ intensity was found and can be observed in Table 1. This table shows the Well-to-Socket (WTS) emissions; this considers not only generation emissions, but the additional emissions attributed to electricity on the All-Ireland grid due to transmission and distribution losses in the network as well as the emissions attributed to the Well-to-Tank (WTT) aspects of the fuel. WTT losses are emissions associated with extraction, refining and transportation of the raw fuel sources to an organisation's site (or asset), prior to their combustion [16].

From Table 1 the average WTS emissions for 2015 can be observed. To help show a more appropriate emissions picture the average daily seasonal trend of $\mathrm{CO}_{2} \mathrm{e}$ intensity for 2015 per $\mathrm{kWh}$ is shown in Fig. 4. From this it can be seen that during the warmer seasons the $\mathrm{CO}_{2} \mathrm{e}$ intensity is considerably higher during the offpeak periods. This is due to the reduced demand, in turn meaning the high-carbon fuels used for base load make up a larger portion of the overall generation, thereby increasing the $\mathrm{CO}_{2} \mathrm{e}$ intensity. This supports the outcome of the off-peak energy tariff emissions shown in Table 2.

Table 1. Average WTS Electricity $\mathrm{CO}_{2} \mathrm{e}$ Breakdown

\begin{tabular}{|c|c|c|c|c|}
\hline Year & $\begin{array}{c}\text { EirGrid } \\
\left(\mathrm{gCO}_{2} \mathrm{e} / \mathrm{kWh}\right)\end{array}$ & $\begin{array}{c}\text { Transmission } \\
\text { Losses }\end{array}$ & WTT & $\begin{array}{c}\text { Total WTS } \\
\text { (gCO } \mathrm{e} / \mathrm{kWh})\end{array}$ \\
\hline 2014 & 537.76 & $\begin{array}{c}(8.25 \%) \\
44.35\end{array}$ & $\begin{array}{c}(16.98 \\
\%) \\
91.29\end{array}$ & 673.39 \\
\hline 2015 & 491.89 & $\begin{array}{c}(8.37 \%) \\
41.16\end{array}$ & $\begin{array}{c}(16.52 \\
\%) \\
81.26\end{array}$ & 614.31 \\
\hline
\end{tabular}

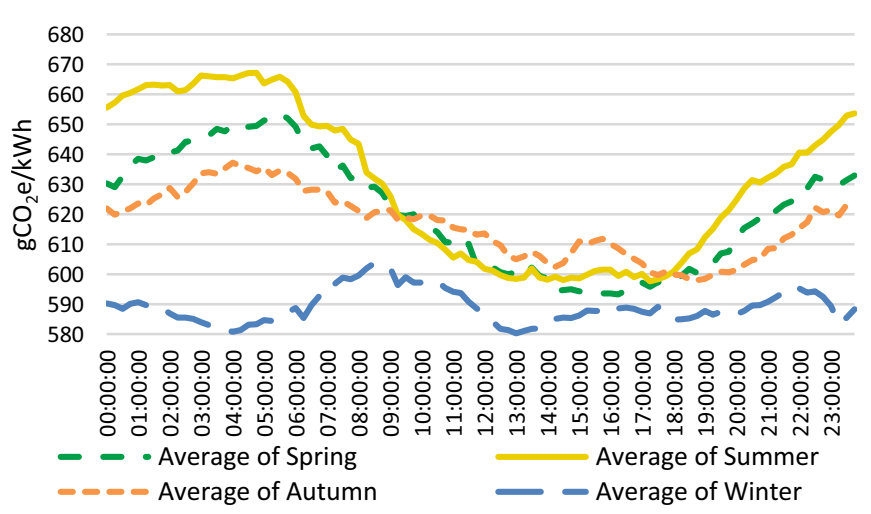

Fig. 1. Average daily seasonal trend of $\mathrm{CO}_{2} \mathrm{e}$ intensity per $\mathrm{kWh}$ for 2015 (WTS of the All-Ireland Grid).

\subsection{Off-peak tariffs and $\mathrm{CO}_{2} \mathrm{e}$ trends}

There are two domestic off-peak energy tariffs available on the island of Ireland, 'Economy 7' used in NI and 
'NightSaver' used in ROI. 'Economy 10' has also been considered in this paper, however it is currently only available in GB. The off-peak times when each tariff is in effect, and the normal occupancy hours for domestic properties, is shown below. Economy 7 and NightSaver tariffs do not adjust for summer time and consequently are one hour behind. Some suppliers adjust Economy 10 for summer time, others do not.

\section{- Economy 7:}

○ 01:00-08:00 (summer 02:00-09:00)

- NightSaver:

- Economy 10:

○ 23:00-08:00 (summer 00:00-09:00)

○ 00:00-05:00, 13:00-16:00, 20:00-22:00

- Normal occupancy hours: [17]

○ Weekday: 07:00-09:00, 17:00-23:00

○ Weekend: 08:00-10:00, 16:00-00:00

Table 2. All-Ireland generation $\mathrm{CO}_{2} \mathrm{e}$ intensity for different electricity tariffs at point of use.

\begin{tabular}{|l|c|}
\hline \multicolumn{1}{|c|}{ Tariff Type } & $\begin{array}{c}\text { Emissions } \\
\text { (gCO2e/kWh) }\end{array}$ \\
\hline Economy 7 & 629.33 \\
\hline NightSaver & 628.78 \\
\hline Economy 10 & 616.59 \\
\hline Normal Occupancy Hours & 611.47 \\
\hline
\end{tabular}

The average annual emissions for each tariff have been calculated and are shown in Table 2. During the off-peak tariff hours, grid emissions are in excess of the average (shown in Table 1), whilst during normal occupancy hours grid emissions are slightly below average. This would seem counterintuitive as wind is stochastic, meaning due to lower off-peak demand wind would likely make up a larger percentage of generation. However, as generation decrease due to lower off-peak demand, the high-carbon fuels used for base load capacity generally reduce by smaller margin than other generation methods. This results in them make up a larger percentage of the overall generation meaning $\mathrm{CO}_{2} \mathrm{e}$ intensity actually increases, this can be seen further on in Figure 1. showing the average daily seasonal trends.

The figures from Table 2 indicate the importance of considering the time of use of electricity in determining the effectiveness of electric heating for carbon emissions reduction.

\subsection{Heating system $\mathrm{CO}_{2} \mathrm{e}$ intensities}

Table 3. BREDEM - space heating efficiency.

\begin{tabular}{|l|c|}
\hline \multicolumn{1}{|c|}{ Space heating system } & $\begin{array}{c}\text { Winter efficiency, } \\
\boldsymbol{\eta}_{\text {winter }}\end{array}$ \\
\hline Typical natural gas/LPG boiler & $80 \%$ \\
New natural gas/LPG boiler & $90 \%$ \\
Typical oil boiler & $80 \%$ \\
New oil boiler & $92 \%$ \\
New electric storage heaters & $100 \%$ \\
\hline
\end{tabular}

For a comprehensive set of efficiency data for a known boiler or system setup, reference should be made to the latest 'Standard Assessment Procedure' (SAP) document
[18] and to the SAP database found at [19], in conjunction with the BREDEM model [11]. Efficiency figures for combustion heating appliances are shown in Table 3.

In SAP and BREDEM documents, winter efficiency is used for the season in which space heating is necessary. In the UK and ROI this is considered to be the whole year, apart for the summer months of June, July and August, whenever usually only water heating is required.

The SAP/BREDEM efficiency figures only consider the heating efficiency of the boilers, as seen in equation 1. To allow for a better comparison against electric heaters the carbon benefits ratio (CBR) was considered, seen in equation 2 [20]. The CBR considers the ratio between the $\mathrm{kWh}$ input to $\mathrm{kWh}$ output of the boilers, when both primary fuel and running electricity are considered.

- $\sigma=$ useful heat delivered $[k W h]$

- $\omega=$ fuel burnt $[k W h]$

- $\gamma=$ electricity used $[k W h]$

- $C E F=$ Carbon Emissions Factor $\left[\mathrm{gCO}_{2} \mathrm{e} / \mathrm{kWh}\right]$

$$
\begin{gathered}
\text { Heat Efficiency }(\%)=\frac{\sigma \times 100}{\omega} \\
C B R(\%)=\frac{\left(\sigma \times C E F_{\text {fuel }}\right) \times 100}{\left(\omega \times C E F_{\text {fuel }}\right)+\left(\gamma \times C E F_{\text {electricity }}\right)}
\end{gathered}
$$

A value for the amount of electricity used by the boilers was calculated using data from a consumer website for the most popular systems of 2015 [21], yielding an average electricity consumption per $\mathrm{kWh}$ of heat output. Boilers will generally use a similar amount of electricity at any output load, meaning this is only accurate when the boilers are running at $100 \%$ load. However, the emission increases due to this are minimal as there is such a high ratio between heating output and electricity use.

The average seasonal $\mathrm{CO}_{2} \mathrm{e}$ intensity of the fossil fuel heating methods based on CBR can be observed in Table 4 , along with their average power outputs and electrical power consumption. The values from Table 3 has been used along with equations 1 and 2 as well as the data collected from the consumer website [21] to calculate these values.

Table 4. 2015 - Average Fossil Fuel Heating $\mathrm{CO}_{2} \mathrm{e}$ Intensity Using CBR and Table 3 Figures

\begin{tabular}{|l|c|c|c|}
\hline \multicolumn{1}{|c|}{ Type } & $\begin{array}{c}\text { Power } \\
\text { Output } \\
\text { (kW) }\end{array}$ & $\begin{array}{c}\text { Electrical Power } \\
\text { Consumption } \\
\text { (kWh) }\end{array}$ & $\begin{array}{c}\text { CBR Emissions } \\
\text { (gCO2e/kWh) }\end{array}$ \\
\hline New Gas & 25.5 & 0.105 & 234.98 \\
\hline Typical Gas & 25.5 & 0.105 & 264.04 \\
\hline New Oil & 25.0 & 0.225 & 328.13 \\
\hline Typical Oil & 25.0 & 0.167 & 376.10 \\
\hline
\end{tabular}

For the comparisons in this paper basic electric heating and night storage heaters have been assumed to be $100 \%$ efficient, meaning their emissions are the same as that of the grid per kWh. However, this is not strictly accurate for night storage heaters. The actual heating efficiency of the storage medium may be $100 \%$, but all of 
this energy is not stored until the time of demand. Some heat will escape, reducing useful effectiveness. These night storage heater problems are greatly reduced when considering newer models, due to their much higher heat retention capabilities. Some vendors of new models of night storage heater claim that their products use $22 \%$ less energy, while being $27 \%$ cheaper to run due to better use of off-peak energy [22].

For the heat pump comparisons in Table 6, the coefficients of performance (COP) have been based on an A16M Dimplex A-Class heat pump running at water output temperatures of $35^{\circ} \mathrm{C}$ and $65^{\circ} \mathrm{C}$ [23]. Some modern heat pumps have been designed to work in different climates with companies making models specifically for the UK and ROI. This means that their performance and efficiencies are designed to work best at typical winter temperatures of between $-2^{\circ} \mathrm{C}$ to $10^{\circ} \mathrm{C}$ [24].

\section{Benefits of Widespread Uptake}

When considering the potential emissions savings of the household, the heating demand of all systems has been based on a typical occupancy of a family of four with active weekday occupancy between 07:00-09:00 and 17:00-23:00, and an active weekend occupancy of 08:0010:00 and 16:00-24:00, as described in [17]. No space heating demand has been considered during the summer months of June, July and August, as per SAP.

The yearly space heating demand of an average household is considered to be $11,704 \mathrm{kWh}$ (based on the average household floor area in ROI [25] together with the average heating energy per floor area in the UK [26]). Based on this space heating demand and the degree days, the average hourly power use per month has been calculated in Table 5 for occupancy and off-peak tariffs, during both weekdays and weekends. These figures have been calculated using historcial data from MET Éireann [27] together with the average space heating demand. The average degree days each month were calculated using the averaged value of 25 weather stations positioned across the ROI, this was then used to scale the yearly space heating demand down to hourly heating demand for each month.

Table 5. 2015 - Average Hourly Heating Demand per Tariff (kWh).

\begin{tabular}{|c|c|c|c|c|c|c|c|c|}
\hline \multirow{2}{*}{ Tariff } & \multicolumn{2}{|c|}{ Occupancy Heating } & \multicolumn{2}{|c|}{ Economy 7} & \multicolumn{2}{|c|}{ NightSaver } & \multicolumn{2}{|c|}{ Economy 10} \\
\hline & $W D$ & $W E$ & $W D$ & $W E$ & $W D$ & $W E$ & $W D$ & $W E$ \\
\hline January & 7.12 & 7.12 & 8.13 & 10.17 & 6.33 & 7.91 & 5.69 & 7.12 \\
\hline February & 7.44 & 7.44 & 8.50 & 10.62 & 6.61 & 8.26 & 5.95 & 7.44 \\
\hline March & 6.42 & 6.42 & 7.34 & 9.17 & 5.71 & 7.14 & 5.14 & 6.42 \\
\hline April & 5.05 & 5.05 & 5.77 & 7.22 & 4.49 & 5.61 & 4.04 & 5.05 \\
\hline May & 3.92 & 3.92 & 4.49 & 5.61 & 3.49 & 4.36 & 3.14 & 3.92 \\
\hline June & 0.00 & 0.00 & 0.00 & 0.00 & 0.00 & 0.00 & 0.00 & 0.00 \\
\hline July & 0.00 & 0.00 & 0.00 & 0.00 & 0.00 & 0.00 & 0.00 & 0.00 \\
\hline August & 0.00 & 0.00 & 0.00 & 0.00 & 0.00 & 0.00 & 0.00 & 0.00 \\
\hline September & 2.32 & 2.32 & 2.65 & 3.32 & 2.06 & 2.58 & 1.86 & 2.32 \\
\hline October & 3.43 & 3.43 & 3.92 & 4.89 & 3.05 & 3.81 & 2.74 & 3.43 \\
\hline November & 4.46 & 4.46 & 5.09 & 6.37 & 3.96 & 4.95 & 3.57 & 4.46 \\
\hline December & 4.99 & 4.99 & 5.70 & 7.13 & 4.44 & 5.55 & 3.99 & 4.99 \\
\hline Heating Hours & 8 & 10 & 7 & 7 & 9 & 9 & 10 & 10 \\
\hline
\end{tabular}

For this paper, typical oil heating has been used as the heating source with which to compare the alternative electric heating methods, meaning it produces $100 \%$ equivalent emissions observed in Table 6 . This is due to the large portion of homes on the island of Ireland which use oil heating, as discussed in Section 2, and the fact that its $\mathrm{CO}_{2} \mathrm{e}$ emissions are the worst of the fossil fuel methods discussed in this paper. The methodology used throughout this paper for the different heating method and emissions figures has been used together with Table 5 , to provide an annual heating emissions comparison with respect to typical oil heating as shown in Table 6 .

From Table 6 it can be observed that the use of basic electric heating as a method of reducing household emissions is currently not very promising, even if offpeak electricity tariffs were considered. The reason for this can be observed in Table 4, looking at the average seasonal emissions for fossil fuels, it can be seen that they are considerably lower than that of the annual grid average (Table 1) or even that of the average hourly seasonal values (Figure. 1). This means that only in very rare occasions is wind generation high enough to reduce WTS emissions sufficiently to offset home heating emissions when compared to fossil fuels.

Table 6. 2015 - Annual Space Heating Emissions Comparison. Emissions of Various Heating Methods with Respect to a Typical Oil Boiler

\begin{tabular}{|l|l|c|}
\hline \multicolumn{1}{|c|}{ Tariff } & \multicolumn{1}{c|}{ Type } & Emissions \\
\hline & Electric Heating & $161.6 \%$ \\
& Typical Oil & $100.0 \%$ \\
Occupancy Heating & New Oil & $87.5 \%$ \\
& Typical Gas & $70.2 \%$ \\
& Heat Pump $65^{\circ} \mathrm{C}$ & $68.1 \%$ \\
& New Gas & $62.5 \%$ \\
\hline Economy 7 & Electric Heating & $164.7 \%$ \\
\hline NightSaver & Electric Heating & $164.4 \%$ \\
\hline \multirow{2}{*}{ Economy 10 } & Electric Heating & $162.1 \%$ \\
& Heat Pump $35^{\circ} \mathrm{C}$ & $39.5 \%$ \\
& & \\
\hline
\end{tabular}


If a conventional oil fired boiler is augmented with an electric boiler, then some emissions savings would be seen. However, with the current electrical generation fuel mix, the electric boiler would only be used for around 10.5 hours in a given year and would only save approximately $0.54 \mathrm{~kg}$ of $\mathrm{CO}_{2} \mathrm{e}$ emissions per year during occupancy hours, shown in Section 2.2.

From Table 6, heat pumps have significant emissions savings over typical oil across all tariffs. However, if heat pumps were to be used in the traditional way during occupancy hours and countries such as the UK adopted $100 \%$ heat pumps, it is believed the electricity demand would increase by $25 \%$, and peak electricity demand by $65 \%$ [28] necessitating the need for smart grid / DSM techniques. To overcome this problem concrete underfloor heating together with a heat pump running at $35^{\circ} \mathrm{C}$ with the Economy 10 tariff [29] offers promise in terms of emissions reduction and reduced grid stress. However, the $35^{\circ} \mathrm{C}$ figure in Table 6 is improbable as an increased demand would be necessary to run heating in this way as it is not an efficient heating storage technique like that of night time storage heaters.

\section{Conclusion}

The concept of implementing electric heating to help reduce household emissions has been considered, using governmental and industrial data. It has been demonstrated that the All-Ireland grid's $\mathrm{CO}_{2} \mathrm{e}$ intensity has not yet reached the point at which it is comparable to fossil fuel heating when using basic electric heating methods. Potential emission savings were shown for an augmented system using an electric boiler together with a typical oil boiler. However, this method proved to provide very little emissions benefit at the present electrical grid $\mathrm{CO}_{2} \mathrm{e}$ intensity. Currently the best option in terms of emissions savings alone is for consumers with an older oil fired boiler to replace this with a new fossil fuel boiler or with a heat pump. It has been shown in this paper that although renewable penetration is high at night, the All-Ireland grid $\mathrm{CO}_{2} \mathrm{e}$ intensity is actual greater during the night than during the day. This is due to low system demand at night fulfilled using high-carbon fuels for system base load. However, the latest generation of night storage heaters are currently running below their potential. The inclusion of a communication network to allow them to be used by the utilities for DSM has potential in helping to increase the SNSP limit. This would mean claims about their use of low carbon electricity could be put into practice through optimisation and scheduling. Furthermore, even though the use of night storage heaters may not reduce household heating emissions, it has a huge effect on the grid's overall running efficiency and emissions by helping to level the demand curve throughout the day. The full extent of the effect/benefit will be considered in future work.

\section{Acknowledgments}

This work was supported and funded by the Engineering and Physical Sciences Research Council (EPSRC) and the Centre for Advanced Sustainable Energy (CASE) project DINOSAURS.

The authors would like to thank EirGrid for providing data to enable this study as well as the CASE grant DINOSAURS. Mr. Kerr would like to thank the EPSRC for funding his $\mathrm{PhD}$ studentship.

\section{References}

1. Sustainable Energy Authority of Ireland, "Energy targets FAQ," [Online]. Available: http://www.seai.ie/Energy-Data-Portal/FrequentlyAsked-Questions/Energy_Targets_FAQ/. [Accessed 2016 March 15].

2. M. Howley, M. Holland and K. O'Rourke, "Renewable energy in Ireland 2012," Sustainable Energy Authority of Ireland, Dublin, 2012.

3. E. McGarrigle, J. Deane and P. Leahy, "How much wind energy will be curtailed on the 2020 Irish power system?," Renewable Energy, vol. 55, pp. 544-553, 2013.

4. A. Neslen, "Wind power generates $140 \%$ of Denmark's electricity demand," The Guardian, 10 July 2015. [Online]. Available: https://www.theguardian.com/environment/2015/jul /10/denmark-wind-windfarm-power-exceedelectricity-demand. [Accessed 06 November 2016].

5. EirGrid Group, "DS3 Programme," EirGrid Group, [Online]. Available: http://www.eirgridgroup.com/how-the-gridworks/ds3-programme/. [Accessed 23 October 2017].

6. Sustainable Energy Authority of Ireland, "Residential energy roadmap," [Online]. Available: http://www.seai.ie/Renewables/Residential_Energy _Roadmap.pdf. [Accessed 21 January 2016].

7. M. Howley, M. Holland and D. Dineen, "Energy in Ireland," Sustainable Energy Authority of Ireland, Dublin, 2014.

8. Central Statistics Office, "Domestic building energy ratings quarter 2 2015," [Online]. Available: http://www.cso.ie/en/releasesandpublications/er/dbe r/domesticbuildingenergyratingsquarter22015/. [Accessed 201603 16].

9. Northern Ireland Neighbourhood Information Service, "Central heating: KS404NI (Settlement 2015)," [Online]. Available: http://www.ninis2.nisra.gov.uk/public/PivotGrid.as $\mathrm{px}$ ?ds $=6665 \& \mathrm{lh}=74 \& \mathrm{yn}=2011 \& \mathrm{sk}=136 \& \mathrm{sn}=$ Censu s\%202011\&yearfilter=. [Accessed 2016 March 16].

10. EirGrid, 06 May 2016. [Online]. Available: http://smartgriddashboard.eirgrid.com/.

11. J. Hart and J. Henderson, "BREDEM 2012 - A technical description of the BRE Domestic Energy Model," BRE, Watford, 2015. 
12. Department of Energy \& Climate Change (DECC), "Government emission conversion factors for greenhouse gas company reporting," Department for Business, Energy \& Industrial Strategy, 01 June 2016. [Online].

Available: https://www.gov.uk/government/collections/govern ment-conversion-factors-for-companyreporting\#conversion-factors-2016. [Accessed 21 October 2016].

13. F. Pallonetto, S. Oxizidis, R. Duignan, O. Neu and D. Finn, "Demand Response Optimisation of AllElectric Residential Buildings in a Dynamic Grid Environment: Irish Case," in 13th Conference of International Building Performance Simulation Association, Chambéry, 2012.

14. J. A. Kelly, M. Fub and J. P. Clinch, "l home heating: The potential for air source heat pump technologies as an alternative to solid and liquid fuels," Energy Policy, vol. 98, pp. 431 - 442, 2016.

15. B. Morvaj, R. Evins and J. Carmeliet, "Decarbonizing the electricity grid: The impact on urban energy systems, distribution grids and district heating potential," Applied Energy, vol. 1991, pp. 125-140, 2017.

16. C. D. R. W. K. J. Nikolas Hill, "Methodology Paper for Emission Factors Final Report," Department of Energy and Climate Change, London, 2015.

17. N. J. Kelly, P. G. Tuohy and A. D. Hawkes, "Performance assessment of tariff-based air source heat pump load shifting in a UK detached dwelling featuring phase change-enhanced buffering," Applied Thermal Engineering, vol. 71, no. 2, p. 809-820, 2014.

18. BRE, "SAP 2012 - The government's standard assessment proceedure for energy rating of dwellings," Watford, 2014.

19. BRE, "Building energy performance assessment support website," [Online]. Available: http://www.ncm-pcdb.org.uk/sap/index.jsp. [Accessed 24 March 2016].

20. G. Orr, T. Lelyveld and S. Burton, "Final Report: In-situ monitoring of efficiencies of condensing boilers and use of secondary heating," GASTEC at CRE Ltd, Cheltenham, 2009.
21. Direct Heating Supplies, "Best boilers to buy 2015," Direct Heating Supplies, 17 December 2014. [Online].

Available: http://www.directheatingsupplies.co.uk/news/bestboilers-buy-2015/. [Accessed 14 January 2016].

22. heatershop, "Product Focus - Dimplex Quantum Storage Heater," heatershop, 02 February 2017. [Online]. Available: https://www.heatershop.co.uk/product-focusquantum-storage-heater. [Accessed 1606 2017].

23. Dimplex, "A-Class - head and shoulders above the competition," [Online].

http://www.dimplex.co.uk/a-

class/features/highoutputtool.htm. [Accessed 13 December 2016].

24. WDS green energy, "Dimplex A Class Air Source Heat Pump," WDS green energy, [Online]. Available:

http://www.wdsgreenenergy.co.uk/dimplex-a-classair-source-heat-pump/. [Accessed 17 May 2017].

25. A. Teicu, "Average Home Sizes of the World Gathered in a Chart," Freshome, 01 August 2011. [Online].

Available: http://freshome.com/2011/08/01/average-homesizes-of-the-world-gathered-in-a-chart/. [Accessed 26 July 2017].

26. OVO Energy Ltd, "How much energy do you use to heat your home?," OVO Energy Ltd, [Online]. Available:

https://www.ovoenergy.com/guides/energyguides/how-much-heating-energy-do-you-use.html. [Accessed 26 July 2017].

27. Met Éireann, "Display and Download Historical Data," Met Éireann, [Online]. Available: http://www.met.ie/climate-request/. [Accessed 14 November 2017].

28. T. Fawcett, R. Layberry and N. Eyre, "Electrification of heating: the role of heat pumps," in BIEE Conference, Oxford, 2014.

29. P. Dunbabin and C. Wickins, "Detailed analysis from the first phase of the Energy Saving Trust's heat pump field trial," Department of Energy and Climate Change, London, 2012. 